\title{
Prevalence of Wild-Type Butyrylcholinesterase Genotype in Patients with Alzheimer's Dementia
}

\author{
Beate Mueller ${ }^{1 *}$, Georg Adler ${ }^{2}$ \\ ${ }^{1}$ Novartis Pharma GmbH, Nürnberg, Germany \\ ${ }^{2}$ Institut für Studien zur Psychischen Gesundheit, Mannheim, Germany \\ Email: "beate-1.mueller@novartis.com
}

Received 19 April 2015; accepted 30 May 2015; published 2 June 2015

Copyright @ 2015 by authors and Scientific Research Publishing Inc.

This work is licensed under the Creative Commons Attribution International License (CC BY). http://creativecommons.org/licenses/by/4.0/

(c) (i) Open Access

\begin{abstract}
Approximately, two-thirds patients with Alzheimer's disease (AD) are reported to have homozygous wild-type butyrylcholinesterase $(\mathrm{BuChE})$ gene expression. It is associated with a higher rate of hydrolysis of acetylcholine, which ultimately leads to increase in the levels of BuChE in advanced stages of the disease. Rivastigmine, a dual inhibitor of acetylcholinesterase (AChE) and BuChE, might be of additional benefit in patients with AD with wild-type BuChE allele.
\end{abstract}

\section{Keywords}

\section{Butyrylcholinesterase, Alzheimer's Disease, Genotype}

\section{Introduction}

Alzheimer's disease (AD) is a neurodegenerative disorder with progressive decline in cognitive function, and accounts for $50 \%-60 \%$ of all dementia cases [1]. The pathological hallmarks of $\mathrm{AD}$ are formation of amyloid plaques by oligomerization of beta-amyloid $(\mathrm{A} \beta$ ) proteins and neurofibrillary tangles (aggregation of tau proteins) [2]. Cholinergic and glutamatergic neurotransmission plays an important role in learning and memory, and current evidence suggests that interference of $\mathrm{A} \beta$ proteins with these pathways may account for neurochemical deficits in $\mathrm{AD}$ [1] [3] [4]. With the progression of $\mathrm{AD}$, acetylcholinesterase (AChE) activity decreases and butyrylcholinesterase (BuChE) activity increases or remains unchanged in certain regions of the brain. Low levels of BuChE in the cerebrospinal fluid have been associated with increased levels of BuChE/AChE/A $\beta$ complexes either surrounding or trapped in the plaques, thereby leading to neuritic tissue degeneration which ultimately "Corresponding author. 
leads to greater cognitive decline in the later stages of the disease [5]-[7]. This is predominantly observed in patients with $\mathrm{AD}$ with homozygous wild-type BuChE gene expression (approximately two-third of patients with $\mathrm{AD}$ ), which has a higher hydrolysis rate than the BuChE K-variant (most common polymorphism of BuChE) [6] [7]. BuChE activity is reported to be higher in men than women suffering from $A D$ [7]. These changes in BuChE activity and BuChE gene expression during the course of AD present a strong possibility that these patients might benefit from the inhibition of BuChE [1].

Current treatment options for AD offer only symptomatic benefit and include cholinesterase inhibitors, such as rivastigmine, donepezil, and galantamine, or $\mathrm{N}$-methyl D-aspartate receptor antagonists such as memantine. Rivastigmine inhibits both $\mathrm{AChE}$ and BuChE with equal potency, whereas donepezil and galantamine primarily target AChE [1]-[5].

Many studies have been conducted to establish the relationship between BuChE genotype and risk of developing $\mathrm{AD}$ and rate of the disease progression [6] [8]-[16]. However, robust evidence is lacking in the clinical practice to understand the effect of wild-type BuChE allele in patients with AD. The main objective of our study was to assess the BuChE genotype in a non-selected population of patients with $\mathrm{AD}$ who had deteriorating symptomatology in the last 6 months and were not treated with rivastigmine. Findings from our study are expected to add to the limited knowledge presently available about the role of wild-type BuChE allele in AD population.

\section{Methods}

BuChE genotype and Alzheimer's dementia

In this multi-center outpatient study, the BuChE genotype was examined in patients with mild-to-moderate$\mathrm{AD}$ exhibiting progressive dementia, either untreated for dementia or treated with donepezil, galantamine or memantine. Demographic characteristics of the study population were recorded. Severity of the disease was estimated using Mini Mental State Examination scores (MMSE; a 30-point questionnaire widely used for estimating the severity of cognitive impairment) and Global Deterioration Scale (GDS; a 7-point rating scale for estimating the magnitude of cognitive and functional capacity) [17] [18]. Inferential statistical examination of relationships between the BuChE genotype and disease severity (for MMSE and GDS) was performed using the Chi-square test.

\section{Results}

A total of 152 patients between the ages 57 - 100 years with MMSE scores 5 - 26 and GDS scores 1 - 7 were included in this study. A majority of the subjects were women (61.2\%) and most of them were treated with donepezil (40.8\%), memantine (26.3\%) or galantamine (15.8\%) and 26 (17.1\%) patients did not undergo anti-dementia drug treatment (Table 1). Among these, 146 (96.1\%) patients carried the wild-type BuChE allele

\begin{tabular}{|c|c|}
\hline Total number of patients, $\mathrm{n}$ & 152 \\
\hline \multicolumn{2}{|l|}{ Sex, n (\%) } \\
\hline Male & 59 \\
\hline Female & 93 \\
\hline Age, years $($ mean \pm SD) & $79.0 \pm 7.3$ \\
\hline Age, years (range) & $57-100$ \\
\hline MMSE score, range (mean \pm SD) & $5-26(18.0 \pm 5.7)$ \\
\hline GDS score, range (mean \pm SD) & $1-7(4.1 \pm 1.4)$ \\
\hline \multicolumn{2}{|l|}{ Treatment, n (\%) } \\
\hline Donepezil & $62(40.8)$ \\
\hline Memantine & $40(26.3)$ \\
\hline Galantamine & $24(15.8)$ \\
\hline No anti-dementia drug treatment & $26(17.1)$ \\
\hline
\end{tabular}

GDS, Global Deterioration Scale; MMSE, Mini Mental State Examination; SD, Standard Deviation. 
with 107 (70.4\%) patients being homozygous and 39 (25.7\%) patients being heterozygous for the gene. The remaining six (3.9\%) patients were homozygous for the $\mathrm{K}$ allele, which is associated with lower levels of circulating BuChE molecules. To study any relationship between the BuChE genotype and disease severity, patients were separated into two groups each, based on the MMSE and GDS scores (MMSE 0 - 15 [ $n=47]$ and MMSE $16-30[n=105]$ and GDS $1-4[n=81]$ and GDS $1-7[n=71])$ and BuChE genotype was then analyzed. There were no significant differences in the MMSE or GDS scores among different BuChE genotype groups ( $\mathrm{p}>$ 0.05 for all groups).

\section{Discussion}

Patients with AD, experiencing deteriorating symptomatology in the last 6 months and who were either untreated or were being treated with a selective AChE inhibitor were included in the present study. Findings from this study indicated that most patients with AD carried the wild-type BuChE. It is predominant in the amyloid plaques and tangles in the form of BuChE protein and is associated with greater cognitive decline, unlike the BuChE-K allele, which is associated with lower expression of enzyme and hence, less rapid cognitive decline in patients with $\mathrm{AD}[7]$.

In an open-label study of 171 Italian patients with $\mathrm{AD}$, no relationship between BuChE genotype and response to rivastigmine, donepezil, or galantamine was reported. However, a limited number of DNA samples from the small sample size and a restricted population pool made it difficult to generalize these results [8]. In a retrospective exploratory analysis from a randomized, placebo-controlled study conducted in 1018 patients with mild cognitive impairment, functional decline in female patients with the BuChE wild-type genotype was significantly reduced by rivastigmine unlike male patients or in patients with the K-allele [19]. Results from retrospective analysis of a 2-year double-blind, parallel group study showed a significant benefit in wild-type BuChE carriers, with less functional decline over 2 years, after treatment with rivastigmine compared with donepezil [20]. Similar favorable responses to rivastigmine were observed in a secondary subgroup analysis of another study [21]. When patients in the ADENA database (pooled data from four 26-week, randomized, double-blind trials of rivastigmine capsules in patients with mild-to moderate $\mathrm{AD}$ ) were grouped by $\mathrm{BuChE}$ genotype, patients with wild-type BuChE showed a significant response to rivastigmine compared with placebo (Novartis, data on file). Furthermore, a number of open-label studies indicated that patients experiencing a lack/ loss of efficacy or intolerance, with donepezil or galantamine (selective AChE inhibitor) demonstrated improved/stabilized symptoms or improved tolerability after switching to rivastigmine (a dual AChE and BuChE inhibitor) [22].

Although this study is limited by a small sample size, findings from our study support previous studies; suggesting the presence of wild-type BuChE allele, resulting in an increased expression of BuChE in the majority of patients with AD. These patients may benefit from switching to rivastigmine, the dual inhibitor of AChE and BuChE. These results also offer the possibility of a rationalized pharmacogenetic approach towards treating and managing $\mathrm{AD}$. Larger studies are warranted to better characterize the relationship between BuChE genotype and treatment response in patients with $\mathrm{AD}$.

\section{Acknowledgements}

The authors would like to thank Preetinder Kaur for providing writing and editorial assistance in the development of this manuscript.

\section{Conflict of Interest}

None.

\section{Disclosures}

This study was sponsored by Novartis Pharma GmbH, Germany. All costs associated with the development and publishing of the present manuscript were met by the sponsor.

Georg Adler received financial support to operate this study.

Beate Mueller is an employee of Novartis Pharma GmbH. 


\section{References}

[1] Noetzil, M. and Eap, C.B. (2013) Pharmacodynamic, Pharmacokinetic and Pharmacogenetic Aspects of Drugs Used in the Treatment of Alzheimer's Disease. Clinical Pharmacokinetics, 52, 225-241. http://dx.doi.org/10.1007/s40262-013-0038-9

[2] De-paula, V.J., Radanovic, N., Diniz, B.S. and Forlenza, O.V. (2012) Alzheimer's Disease. Subcellular Biochemistry, 65, 329-352. http://dx.doi.org/10.1007/978-94-007-5416-4_14

[3] Schliebs, R. and Arendt, T. (2006) The Significance of the Cholinergic System in the Brain during Aging and in Alzheimer's Disease. Journal of Neural Transmission, 113, 1625-1644. http://dx.doi.org/10.1007/s00702-006-0579-2

[4] Francis, P.T. (2003) Glutamatergic Systems in Alzheimer’s Disease. International Journal of Geriatric Psychiatry, 18, S15-S21. http://dx.doi.org/10.1002/gps.934

[5] Anand, P. and Singh, B. (2013) A Review on Cholinesterase Inhibitors for Alzheimer's Disease. Archives of Pharmacal Research, 36, 375-399. http://dx.doi.org/10.1007/s12272-013-0036-3

[6] Holmes, C., Ballard, C., Lehman, D., David Smith, A., Beaumont, H., Day, I.N., Nadeem Khan, M., Lovestone, S., McCulley, M., Morris, C.M., Munoz, D.G., O’Brien, K., Russ, C., Del Ser, T. and Warden, D. (2005) Rate of Progression of Cognitive Decline in Alzheimer's Disease: Effect of Butyrylcholinesterase K Gene Variation. Journal of Neurology, Neurosurgery \& Psychiatry, 76, 640-643. http://dx.doi.org/10.1136/jnnp.2004.039321

[7] Nordberg, A., Ballard, C., Bullock, R., Darreh-Shori, T. and Somogyi, M. (2013) Prim Care Companion CNS Disord. A Review of Butyrylycholinesterase as a Therapeutic Target in the Treatment of Alzheimer's Disease, 15, 1-18.

[8] Chianella, C., Gragnaniello, D., Delser, P.M., Visentini, M.F., Sette, E., Tola, M.R., Barbujani, G. and Fuselliet, S. (2011) BCHE and CYP2D6 Genetic Variation in Alzheimer's Disease Patients Treated with Cholinesterase Inhibitors. European Journal of Clinical Pharmacology, 67, 1147-1157. http://dx.doi.org/10.1007/s00228-011-1064-X

[9] Bizzarro, A., Guglielmi, V., Lomastro, R., Valenza, A., Lauria, A., Marra, C., Silveri, M.C., Tiziano, F.D., Brahe, C. and Masullo, C. (2010) BuChE K Variant Is Decreased in Alzheimer's Disease Not in Fronto-Temporal Dementia. Journal of Neural Transmission, 117, 377-383. http://dx.doi.org/10.1007/s00702-009-0358-y

[10] Sodeyama, N., Yamada, M., Itoh, Y., Otomo, E., Suematsu, N. and Matsushita, M. (1999) Association between Butyrylcholinesterase K Variant and the Alzheimer Type Neuropathological Changes in Apolipoprotein E Epsilon4 Carriers Older than 75 Years. Journal of Neurology, Neurosurgery \& Psychiatry, 67, 693-694. http://dx.doi.org/10.1136/jnnp.67.5.693

[11] Russ, C., Powell, J., Lovestone, S. and Holmes, C. (1998) K Variant of Butyrycholinesterase and Late-Onset Alzheimer's Disease. The Lancet, 351, 881. http://dx.doi.org/10.1016/S0140-6736(05)70292-0

[12] Singleton, A.B., Smith, G., Gibson, A.M., Woodward, R., Perry, R.H., Ince, P.G., Edwardson, J.A. and Morris, C.M. (1998) No Association between the K Variant of the Butyrylcholinesterase Gene and Pathologically Confirmed Alzheimer's Disease. Human Molecular Genetics, 7, 937-939. http://dx.doi.org/10.1093/hmg/7.5.937

[13] Yamamoto, Y., Yasuda, M., Mori, E. and Maeda, K. (1999) Failure to Confirm a Synergistic Effect between the KVariant of the Butyrylcholinesterase Gene and the Epsilon4 Allele of the Apolipoprotein Gene in Japanese Patients with Alzheimer's Disease. Journal of Neurology, Neurosurgery \& Psychiatry, 67, 94-96. http://dx.doi.org/10.1136/jnnp.67.1.94

[14] Kehoe, P.G., Williams, H., Holmans, P., Wilcock, G., Cairns, N.J., Neal, J. and Owen, M.J. (1998) The Butyrylcholinesterase K Variant and Susceptibility to Alzheimer's Disease. Journal of Medical Genetics, 35, 1034-1035. http://dx.doi.org/10.1136/jmg.35.12.1034

[15] Grubber, J.M., Saunders, A.M., Crane-Gatherum, A.R., Scott, W.K., Martin, E.R., Haynes, C.S., Conneally, P.M., Small, G.W., Roses, A.D., Haines, J.L. and Pericak-Vance, M.A. (1999) Analysis of Association between Alzheimer's Disease and the K Variant of Butyrylcholinesterase (BCHE-K). Neuroscience Letters, 269, 115-119. http://dx.doi.org/10.1016/S0304-3940(99)00426-7

[16] Lane, R., He, Y., Morris, C., Leverenz, J.B., Emre, M. and Ballard, C. (2009) BuChE-K and APOE $€ 4$ Allele Frequencies in Lewy Body Dementias, and Influence of Genotype and Hyperhomocysteinemia on Cognitive Decline. Movement Disorders, 24, 392-400. http://dx.doi.org/10.1002/mds.22357

[17] Folstein, M.F. and Folstein, S.E. (1975) A Practical Method for Grading the Cognitive State of Patients for the Clinician. Journal of Psychiatric Research, 12, 189-198. http://dx.doi.org/10.1016/0022-3956(75)90026-6

[18] Reisberg, B., Ferris, S.H, de Leon, M.J. and Crook, T. (1988) Global Deterioration Scale (GDS). Psychopharmacology Bulletin, 24, 661-663.

[19] Ferris, S., Nordberg, A., Soininen, H., Darreh-Shori, T. and Lane, R. (2009) Progression from Mild Cognitive Impairment to Alzheimer's Disease: Effects of Sex, Butyrylcholinesterase Genotype, and Rivastigmine Treatment. Pharmacogenetics and Genomics, 19, 635-646. http://dx.doi.org/10.1097/FPC.0b013e32832f8c17 
[20] Bullock, R., Touchon, J., Bergman, H., Gambina, G., He, Y., Rapatz, G., Nagel, J. and Lane, R. (2005) Rivastigmine and Donepezil Treatment in Moderate to Moderately-Severe Alzheimer's Disease over a 2-Year Period. Current Medical Research \& Opinion, 21, 1317-1327. http://dx.doi.org/10.1185/030079905X56565

[21] Blesa, R., Bullock, R., He, Y., Bergman, H., Gambina, G., Meyer, J., Rapatz, G., Nagel, J. and Lane, R. (2006) Effect of Butyrylcholinesterase Genotype on the Response to Rivastigmine or Donepezil in Younger Patients with Alzheimer's Disease. Pharmacogenetics and Genomics, 16, 771-774. http://dx.doi.org/10.1097/01.fpc.0000220573.05714.ac

[22] Massoud, F., Desmarais, J.E. and Guathier, S. (2010) Switching Cholinesterase Inhibitors in Older Adults with Dementia. International Psychogeriatrics, 23, 372-378. http://dx.doi.org/10.1017/S1041610210001985 